\title{
FINITE ELEMENT MODELING OF RESISTIVITY DATA FROM KIMBERLITES IN COLORADO-WYOMING, USA.
}

\author{
$M_{e m m i}^{(1),(2)}, J . M$. and McCallum ${ }^{(1)}, M . E$.
}

(1) Department of Earth Resources, Colorado State University, Fort Collins, CO 80523 USA; (2) Present address: Department of Geological Sciences, Ohio State University, Columbus, OH 43210 USA.

The geoelectric character of three Colorado-Wyoming kimberlite occurrences has been defined via two dimensional finite element intrinsic resistivity inversion. Collinear dipole-dipole resistivity surveys were conducted across the. Maxwell 2 pipe, IM36 blow and Sheep Rock 1 (Radichal) diatreme of the State Line, Iron Mountain and Sheep Rock districts respectively, of the Colorado-Wyoming Kimberlite Province. Each of the investigated kimberlite bodies is responsible for a lowhigh-low "inverted $V$ " pattern in apparent resistivity (Figure 1-A). Such an anomaly typifies a vertical conductor. Colorado-Wyoming kimberlite is 8 to 15 times less resistive than crystalline country rocks $(100-225$ ohm-m for kimberlite versus 1000 - 2500 ohm-m for host rocks).

Following detailed interpretation of the pseudosections of apparent resistivity from each of the three kimberlites, the apparent resistivity data were subjected to finite element modeling to test the efficacy of this technique in producing two dimensional intrinsic resistivity models of kimberlite bodies and country rocks (Figure 1-B). For each pseudosection, the modeling procedure involved (1) centering the kimberlite body as a vertical tabular conductor in the finite element mesh, along with delineating vertical and lateral inhomogeneities in intrinsic resistivity throughout the pseudosection; and, (2) computing models iteratively, varying widths, depths, depth extent, locations and intrinsic resistivities of geologic inhomogeneities and the vertical tabular conductor, until an acceptable fit (average error of $30 \%$ ) was obtained between the observed pseudosection and the model pseudosection (compare Figure $1-A$ and Figure $1-C$ ).

The finite element models show that evaluated colorado-Wyoming kimberlite occurrences are represented adequately by a two layered vertical tabular conductor, with the upper layer corresponding to weathered kimberlite and the lower layer equating to more massive kimberlite (Figure 1-B). Intrinsic resistivity of Colorado-Wyoming kimberlite ranges from 20 to $50 \mathrm{ohm}-\mathrm{m}$ compared to values of 1000 to 3000 ohm-m for crystalline host rocks. 


\section{Figure 1}

(A) West to east pseudosection of logarithmic apparent resistivity (in ohm-meters) across the Maxwell 2 kimberlite diatreme, State Line Kimberlite District, Colorado. Numbers on vertical axis correspond to inter-dipole or " $n$ " spacing. Strip above profile indicates geology inferred from data compared with mapped contacts.

Interpretive strip explanation: triangle = apparent center of diatreme, black = kimberlite anomaly, stippled pattern = Sherman Granite, thick line = fault or major joint, thin white line = mapped kimberlite/granite contact.

(B) West to east two dimensional finite element intrinsic resistivity model across the Maxwell 2 kimberlite diatreme, State Line Kimberlite District, Colorado. Numbers on vertical axis correspond to inter-dipole or " $n$ " spacing.

Media and intrinsic resistivities (in ohm-m) are: $3000-2000=$ Sherman Granite, $700=$ grus, $200-100=$ grus and weathered kimberlite float, $100($ shaded area $)=$ kimberlite, 20 = weathered kimberlite.

(C) West to east model logarithmic pseudosection of apparent resistivity (in ohm-meters) across the Maxwell 2 kimberlite diatreme, State Line Kimberlite District, Colorado. Numbers on vertical axis correspond to inter-dipole or " $n$ " spacing. (See A above for explanation of interpretive strip).
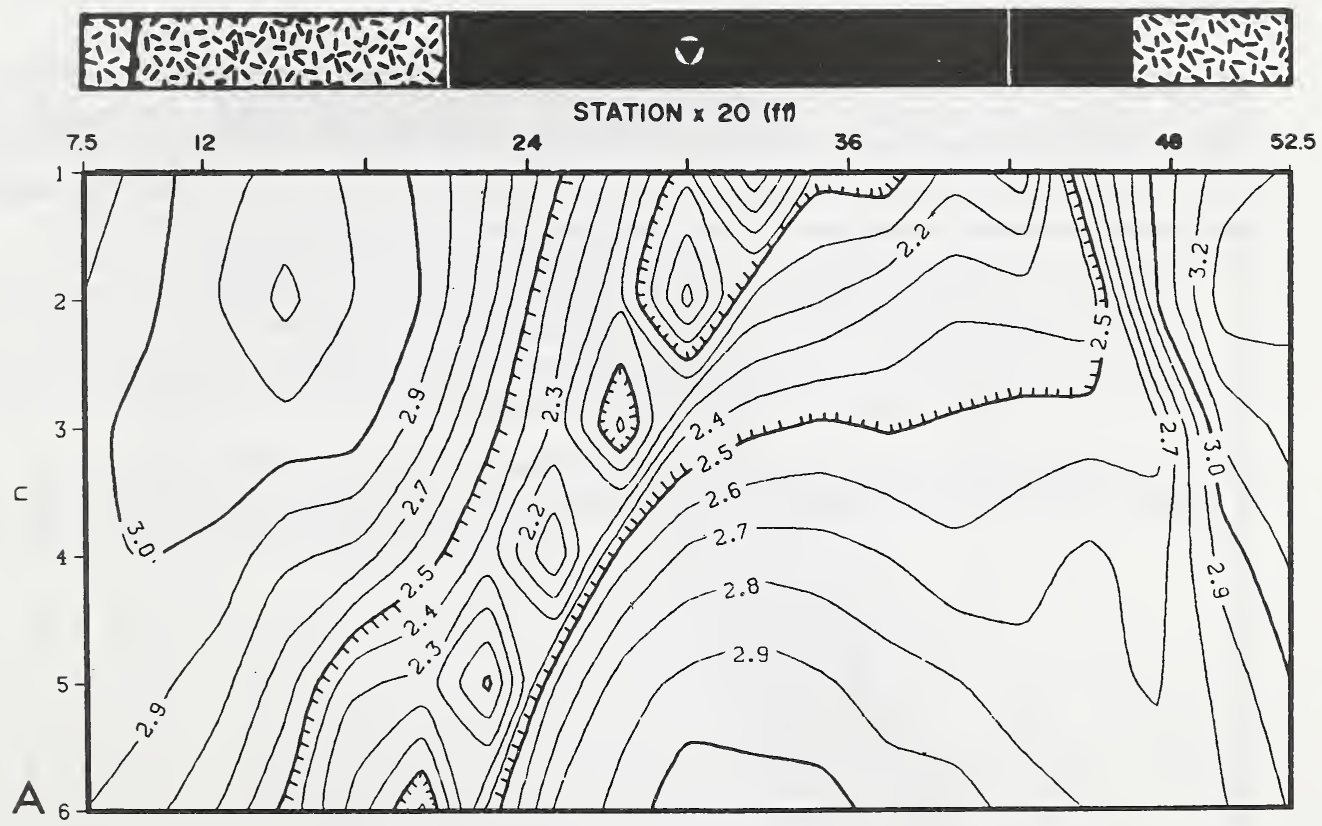

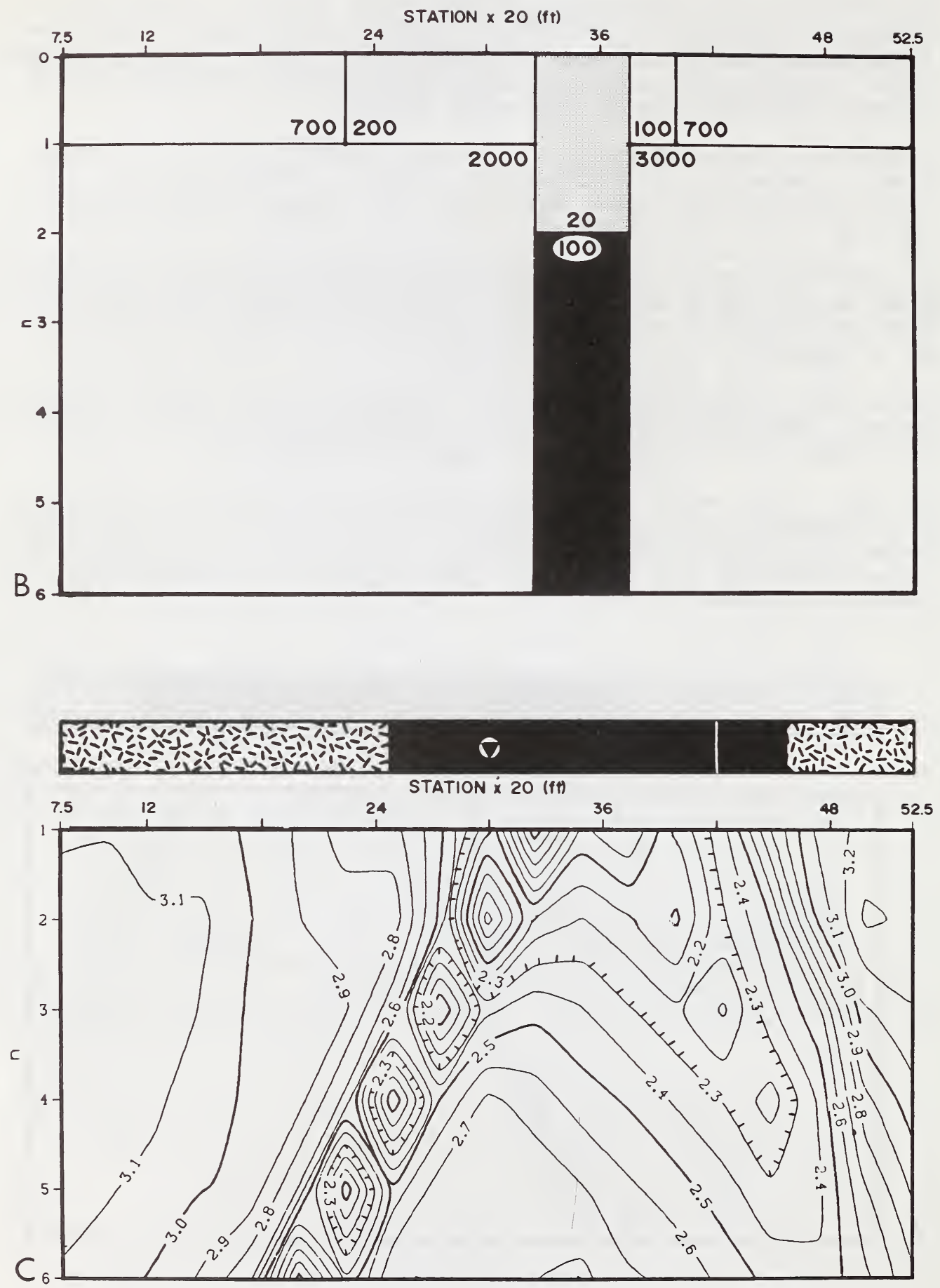